\title{
Prevent in a Northern Town
}

\author{
Joan McLaughlin interviewed by Stephen Cowden
}

*Correspondence: s.cowden@coventry.ac.uk

Joan McLaughlin is an FE teacher at a Further Education College in a multicultural area in the north of England. She was interviewed by Stephen Cowden, one of the editors of this issue, to discuss her experience of teaching around many of the issues associated with Prevent.

Stephen: To start with, Joan, we're going to be talking about the work you do at your College. Could you start by telling us what kind of institution it is, what kind of students do you work with, what kind of area the college is located in?

Joan: I am a course leader. Typically I work with Pakistani women, who are the majority of my students. I am a course leader on the BTEC Level 1, 2, and 3 Health and Social Care. I work with students of various ages

(C) Copyright: The Authors. This article is issued under the terms of the Creative Commons Attribution Non-Commercial Share Alike License, which permits use and redistribution of the work provided that the original author and source are credited, the work is not used for commercial purposes and that any derivative works are made available under the same license terms. and abilities, from school leavers at 16 to mature learners - for example, I have some students who are 46 years of age. I'm teaching mums, kids straight from school, so quite a variety of students.

The area I work in is quite unique; it's got its own personality and demographic. It's a working class area and a medium-size town. It's an area that suffers from quite a lot of economic and social deprivation, so the area gets quite a lot of bad press - a lot of different things have gone on there. It has a large Asian population, so large amounts of students at the college are from a Pakistani background; these are the majority of 
the students on my course. The college also has a lot of men on other courses, such as engineering and construction.

Stephen: You teach on a BTEC Health and Social Care programme?

Joan: Yes, and within that programme there are group tutorials with a set agenda of topics that we have to teach for all students under 19. The Set Topics are subjects like child exploitation, forced marriage, female genital mutilation - and the 'British values' and the Prevent strategy are also covered here. All of these are incredibly sensitive issues.

Stephen: OK, let's talk a little bit about the way you are asked to incorporate material from the counter-terrorism policy Prevent into your teaching. How did you find it, trying to introduce this material?

Joan: Initially we'd been given a very skeletal training, just an outline, really - maybe half a day's training in all. This was undertaken by a local police officer.

Stephen: How did you find the training?

Joan: It was just really a PowerPoint discussion, not a lot of discussion: highlighting why Prevent is important, what to look out for, things like lots of interest in religion, lots of praying, people being withdrawn, unusual behaviour, maybe aggression, extreme behaviour ... but to be honest, the students that we teach, in my college, that behaviour wouldn't be a rare thing anyway because a lot of kids suffer from loads and loads of personal and social issues, so just because somebody becomes aggressive or withdrawn, that wouldn't make you say 'aha here comes the Prevent policy'.

Stephen: So you're saying the training wasn't that helpful?

Joan: Not really. And anyway, this was a while ago. We haven't had any real training other than some resources we were given. We look through the resources we've been given and then we tailor them to how we 
teach, or we just use them if you don't feel confident enough to change things.

Stephen: So it sounds like the training you received didn't really offer you or the staff you work with much guidance?

Joan: No, it was almost like inducing some kind of hysteria, to be honest. People getting really afraid, lacking in confidence to deal with the issues, people really worried that if they missed something would they be held culpable for it ...

Stephen: So the training tended to raise staff anxiety ...?

Joan: Staff don't feel confident in dealing with these topics. But it's mandatory, especially for the 'British Values'i material - it's something that Ofstedii are very, very keen on so obviously, as a college, you want to meet the requirements.

Stephen: So it's an Ofsted requirement?

Joan: The 'British values' component is, definitely.

Stephen: So tell me, Joan, how did the students respond when you tried to incorporate this material as you were required to?

Joan: Initially, the students didn't know what 'Prevent' was which was quite interesting, and I think the name in itself doesn't reflect the enormity of the issue. So I would say, 'What do you think Prevent is?' and the student would say, 'Is it something to do with preventing bullying or something like that?' So I had to introduce the topic with them, which was surprising, as they didn't really get what I was about. Because it was very key in college. Then I have to explain what it was about and I could see immediately the shutdown from the students - they felt judged, especially from a white woman stood in front of a class full of Asian girls. They'd think I was making a judgement about them. Because it does seem that when we do teach about Prevent, it's all about ISIS. So, I make sure I bring up things like the EDL and right-wing groups first of all. 
Stephen: You make sure you introduce the far right, which is also part of Prevent?

Joan: Yes but it seems that the things we are given are all about ISIS.

Stephen: And Islamist extremism?

Joan: Yes. So I make sure that I don't bring that up first, but as soon as I bring up the word I can see the students are thinking, 'Oh God, here we go.' Shut down, they feel really defensive, they aren't interested. Discussion is very minimal. They feel fearful, if they say something they might be exposing themselves in some way. They would probably be afraid to show if they've got any political affiliation to any sort of group. So it's just like me preaching from the front of the class.

Stephen: The context you're describing is one where it's really difficult to raise what is, in actual fact, a really important issue.

Joan: Yes. I think some of them get it if I talk about the right-wing stuff and the IRA, and I do sometimes bring in my own family's experience my mum came from Northern Ireland and she experienced lots of terror in her lifetime from both the IRA and the Protestant extremist groups. So I talk about that to make they feel they feel they are in some sort of safe zone, that I'm not judging them, that I have some sort of understanding. But whether that gets through ....

Stephen: So these are your own personal strategies you've developed?

Joan: Yes - and I'm actually not sure whether I should be doing that, but anyway I do. Because it makes them feel less judged and hopefully less defensive.

Stephen: What you're describing here is a mostly young, British Asian population that really should be one of the groups that the Prevent policy is most trying to reach and address the concerns of, and yet the framing of the policy, not to mention the lack of training people in your position have received, means that this group end up experiencing the discussion 
of that as something that is judging them - they are feeling defensive, judged, they are nervous about talking in class, because they fear that anything they say might be used against them. That suggests to me that this is basically a really bad way of getting through to them - that's what coming through from what you've said. It's also worth noting that the way that you've been able to overcome some of those problems and try to forge a connection is a strategy that you have developed entirely yourself, and which didn't come any of the formal training you were offered.

Joan: I feel it's just a tick box. Have we talked about Prevent? Tick. Have we talk about 'British Values'? Tick. Regardless of the impact it has on the students. And I don't feel comfortable as a teacher discussing things like that, because I don't feel I've had enough training.

Stephen: Talking about the 'British Values' material, you mention that this is part of your Ofsted inspection as it would be for all Further Education colleges. How do you feel about the term 'British Values' and how do your students respond to this?

Joan: Well, initially, I didn't like the words 'British Values'. I used to talk about 'Human Values' when I delivered it, but then we were told by our managements that we have to use the term 'British Values'. We have had some interesting training for that and there was some recognition about how uncomfortable the staff were with that.

Stephen: What was that about?

Joan: Teaching staff were saying we felt uncomfortable because it's not just 'British Values'- we felt it was much better to talk about 'human values'. So what was agreed was that we would focus these sessions on 'what sort of values do you think you need to have in order to go forward and be successful in British society' - which I thought was a much better way of delivering it. So I thought, this was much better, and I got the 
students to do some poster work and we talked about democracy, law, tolerance, and things like that.

Stephen: And how did the students feel about that?

Joan: Better. Better, because they could relate to what was being said rather than this generic term 'British Values'. It's about what values did they need to have to succeed.

Stephen: And when you reframed it like that, students could relate to it? Joan: Yes, because we talked about what kind of things could you do which is a democratic activity in college. So, for example, we had an opportunity to vote in the student election. So they could actually relate to what these values were. We talked about Anti-bullying, things like that, respecting class boundaries. So they could relate to it a bit more. We related it to employability, going forward in the society - stuff like that.

Stephen: So the way you adapted this, was this just something you did yourself?

Joan: No, it was from the training - we had a staff training. Every week we have a training - different topics, different guest speakers. It was from that.

Stephen: So there was some training you had that was useful?

Joan: Yes, definitely.

Stephen: So you've talked about how you've tried to address students' defensiveness regarding this question of 'Prevent', and how you developed your own strategies, still noting that the students showed a lot of defensiveness. You also have described a situation where, following the Manchester Arena bombing (22 May 2017), many of your Asian students came in and you described them as 'quite sheepish'. 
Joan: Yes, following this event, the way it affected the students was that they thought they were being judged by any white member of the college. Their classmates, for example. They were afraid that they were being judged, and they would be called names, made a scapegoat of. They were quiet, and then it's difficult to talk about a current issue in class. They may have thought people were forming an opinion on 'their culture'.

Stephen: There's a desperate need to open up a space to talk about these issues in a situation like that, but what you are saying is how difficult that was to do.

Joan: Yes, especially when I would never have that kind of opinion. For somebody like me, for the students [to] think I would - I find that in itself really difficult.

Stephen: So there's a whole level of polarisation that you're just working with all the time.

Joan: Especially if you don't know your students, if it's early on. With the second years it's easier, we get to know each other.

Stephen: Have you found it any easier to generate discussion with these students who you've developed more of a relationship with? What kind of things would come out of discussions?

Joan: They would know I'm not judging them. They would be more open to talking about what's going in the news. They talk about how they've been called names in the town centre, how other people have judged them, how they feel terrible about what's going on. If they say how badly they're feeling, people smirk and laugh at them.

Stephen: The sense that they are, as Muslims, disgusted by the actions of ISIS, but that is a view that's very hard for them to express in the wider society. 
Joan: Yes, unless they're in the trusting zone. In the first year, you're finding your way.

Stephen: Ok, you've given a sense of what it's like in a sort of multicultural, working class community where you work. Have there been any other things relevant to this discussion that have happened at your college?

Joan: One other thing that I would really like to mention was a talk we had from an outside speaker, Mike Haines. He was brought in as part of a Student Enrichment Programme where we have guest speakers that come in and talk about a variety of topics - like drink driving, mental health, bullying of 'emos' which resulted in a girl being murdered. Attendance is voluntary for these events, but I stressed to my students that it was important to go to. Mike Haines was the brother of David Haines who was murdered by ISIS in Syria. He was a humanitarian worker who went over to Syria, ironically enough. So I presented this to the class. I explained what it was about. It was presented to me as part of the Prevent strategy. As soon as I said the words Prevent I had 'Oh God, do we have this again, why do we have to go, we hate this stuff, people are looking at us, why do we have to go.' I said, listen, let's just go and see what it's about. It looks really interesting and it might be a different slant on what we're usually talking about. And when we went, the fellow delivered his story in such a powerful way, they just completely embraced what Prevent was about. It was like, 'God, if we'd had this in the beginning, it might have been a lot easier.'

Stephen: So tell me, what did Mike Haines do that had such a profound impact?

Joan: I think, the fact that he talked about terrorism not from just one culture's point of view. He gave a complete overriding picture of what terror was, how it affects people from all cultures. He picked people out from the audience, asked them where they came from and how they felt 
their culture was represented and how they felt about it. He wasn't just talking to one group; he was talking to the whole college audience. And I think, the fact that he talked about how he doesn't see ISIS as part of the student's Muslim culture. It's a separate thing, completely separate, and he made it so separate. He presented information about how he made great friends with Imams, and he just came across as someone with a really wide knowledge of the world.

Stephen: So Mike was not in Syria with his brother, but he travelled over there subsequent to the killing of his brother by ISIS?

Joan: That's right. His focus now is doing work to stop hate between cultures. He talks about the way ISIS and any other terrorist group does not fit in to what religion is, even though they are using this as their platform.

Stephen: And so it was through those kind of strategies, that kind of direct personal experience of the issues, that he was able to get through to the students and overcome their defensiveness?

Joan: You could almost hear a collective sigh of relief that they weren't being judged by this man who had had his brother killed by a Muslim group. So they could see that they weren't being judged, that he had no hatred. It was all about coming together as one to stop this. And kind of explaining the culture of creating fear and hatred between groups and how that needs to be stopped, and that's what Prevent is about.

Stephen: So his work was part of Prevent?

Joan: It was about how do we stop this, it wasn't just report, report, report and be like a big brother eye on everybody; it was more about restorative work. Get people understanding why terror groups want to polarise people and create hate.

Stephen: And those were the words he used? 
Joan: Yes. There was one moment where somebody asked him why he didn't hate the people who killed his brother. He said, 'If I hate them, they've won. And it's not about that - it's about understanding each other and building bridges.'

Stephen: So, in the sense, what you've described are very different experiences which have taken place under the auspices of Prevent. On the one hand, you thought the training you received from the local police was very inadequate and really not helpful to the kind of work you're doing.

Joan: More scaremongering.

Stephen: Then you described a really positive work by Mike Haines, also undertaken under the auspices of Prevent, where some really effective work was being done, and where this was linked into creating a really powerful anti-hate message.

Joan: Students were crying. They were really touched and emotional about it. One of my students wanted to email him to talk about the impact he'd had on her. The feedback he gets across communities is really positive.

\section{References:}

More information about the Mike Haines work can be found at https://mikehaines.globalactsofunity.com/

\section{To cite this article:}

McLaughlin, J. and Cowden, S. (2019) Prevent in a Northern Town: Joan McLaughlin interviewed by Stephen Cowden. Feminist Dissent, 4, pp 235245. Retrieved from: https://doi.org/10.31273/fd.n4.2019.322 


\footnotetext{
'The terminology reflects the UK government's definition of extremism within the Prevent Duty as: "vocal or active opposition to fundamental British values, including democracy, the rule of law, individual liberty and mutual respect and tolerance of different faiths and beliefs."

(https://preventforfeandtraining.org.uk/home/support-staff/what-do-i-need-to-know/)

ii The terminology reflects the UK government's definition of extremism within the Prevent Duty as: "vocal or active opposition to fundamental British values, including democracy, the rule of law, individual liberty and mutual respect and tolerance of different faiths and beliefs."

(https://preventforfeandtraining.org.uk/home/support-staff/what-do-i-need-to-know/)
} 